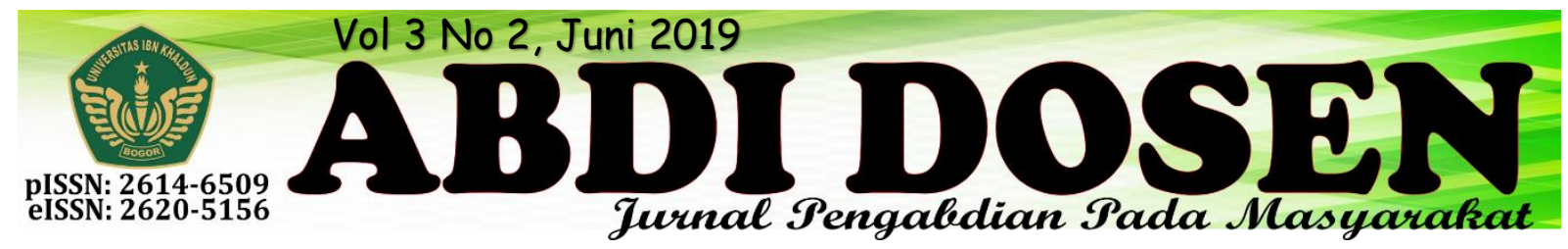

\title{
BERSAMA MEMAJUKAN DESA
}

\author{
Andreanda Nasution ${ }^{1}$, Akbar Maulana, Dedi Kurniawan ${ }^{2}$ \\ andreanda@uika-bogor.ac.id ${ }^{1}$ \\ akagamiowner@gmail.com $^{2}$ \\ Fakultas Kesehatan Universitas Ibn Khaldun ${ }^{1}$, Mahasiswa KKN Kelompok 45 Tahun $2018^{2}$
}

\begin{abstract}
ABSTRAK
Tujuan diselenggarakannya program Kuliah Kerja Nyata $(\mathrm{KKN})$ yaitu untuk menumbuh kembangkan empati dan kepedulian mahasiswa terhadap berbagai permasalahan yang dihadapi masyarakat dan pembangunan yang mewujudkan mencerdaskan kehidupan dan kesejahteraan masyarakat. Peneliti melaksanakan KKN di Desa Gunung Bunder II Kecamatan Pamijahan, Kabupaten Bogor dengan luas wilayah $386.450 \mathrm{Ha}$. Sasaran dalam penelitian ini dilaksanakan di kampung Pasir Putih RT 04/RW 04, Desa Gunung Bunder II, dengan jumlah penduduk 9.355 jiwa yang terdiri dari 4.632 laki-laki dan 4723 perempuan dengan jumlah kepala keluarga sebanyak 2.871 KK. Mata pencaharian masyarakat Desa Gunung Bunder II di dominasi oleh buruh tani yang berjumlah 1550 orang. Adapun sarana pendidikan di Desa Gunung Bunder II yaitu PAUD, SD/MI dan MTS. Metode yang dilakukan dalam penelitian ini yaitu wawancara, observasi, pendekatan, sosialisasi dan penyuluhan kepada masyarakat. Untuk mewujudkan tujuan yang diharapkan oleh peneliti, peneliti membuat 12 program kerja dan satu program dalam momen besar HUT RI ke 73 dengan total 13 program kerja yang dilaksanakan dalam kurun waktu 30 hari. Masyarakat sangat antusias dalam program kerja yang telah direncanakan oleh peneliti. Namun ditemukan hambatan dalam pemasaran hasil dari ekonomi kreatif, sehingga perlunya kerjasama lintas sektor yang diharapkan dapat meningkatkan perekonomian masyarakat Desa Gunung Bunder II, Kecamatan Pamijahan, Kabupaten Bogor.
\end{abstract}

\section{Kata Kunci : Bersama Memajukan Desa, Kuliah Kerja Nyata, Desa Gunung Bunder II.}

\section{PENDAHULUAN}

Kuliah Kerja Nyata adalah proses kegiatan pengabdian kepada masyarakat dalam berbagai segi kehidupan bermasyarakat. Kuliah Kerja Nyata (KKN) adalah bagian dari sistem pendidikan tinggi agar mahasiswa hidup ditengah-tengah masyarakat untuk membantu dan mendampingi masyarakat memanfaatkan potensi sumber daya alam (SDA) lokal dan sumber daya manusia (SDM) (Suyono \& Haryanto, 2009, p. 7). KKN merupakan proses pembelajaran bagi mahasiswa $\mathrm{S} 1$ Universitas Ibn Khaldun (UIKA) yang bertujuan untuk menumbuh kembangkan empati dan kepedulian civitas UIKA terhadap berbagai permasalahan yang dihadapi masyarakat dan pembangunan yang mewujudkan mencerdaskan kehidupan dan kesejahteraan masyarakat. Peneliti bersama-sama untuk memajukan Desa Gunung Bunder II Kecamatan Pamijahan, Kabupaten Bogor khususnya Kampung Pasir Putih RT 04/RW 04 agar menjadi masyarakat yang aktif, kreatif, peduli dan berakhlak melalui rangkaian program yang sudah direncanakan. Desa 
Gunung Bunder II mempunyai luas wilayah 386.450 Ha. Dengan jumlah penduduk 9.355 jiwa yang terdiri dari 4.632 laki-laki dan 4.723 perempuan dengan jumlah kepala keluarga sebanyak 2.871 KK. Mata pencaharian penduduk di desa ini diantaranya petani berjumlah 1.325 orang, buruh tani 1.550 orang, pedagang 200 orang, pegawai negeri sipil 20 orang, karyawan swasta 20 orang, wirausaha 38 orang, buruh harian 200 orang, tidak bekerja 230 orang. Sarana pendidikan Desa Gunung Bunder II terdiri dari TK/PAUD

\section{METODE}

Metode yang dilakukan dalam pelaksanaan rangkaian program $\mathrm{KKN}$ Tematik 2018 oleh kelompok 45 yaitu dengan cara wawancara terhadap tokoh masyarakat dan pegawai kantor desa di Desa Gunung Bunder II. Wawancara adalah suatu kegiatan yang dilakukan untuk mendapatkan informasi secara langsung dengan mengungkapkan pertanyaanpertanyaan pada para responden. Wawancara bermakana berhadapan langsung antara interview dengan responden, dan kegiatannya dilakukan

\section{REALISASI PROGRAM}

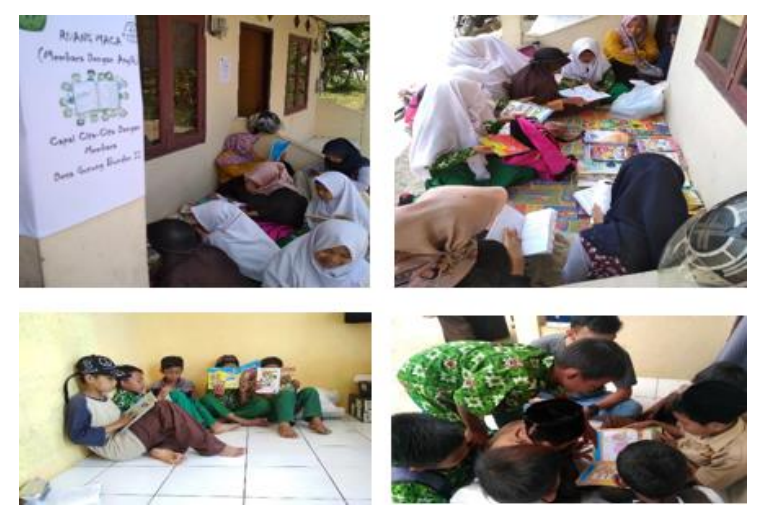

\section{Ruang MACA (Ruang Membaca dengan} Asyik)

Program kerja ruang maca dilaksanakan sejak tanggal 9 Agustus 2018, hari Senin, berjumlah 2 unit, SD berjumlah 3 unit, MI berjumlah 2 unit, SLTP berjumlah 2 unit, MTS berjumlah 1 unit dan belum tersedianya sekolah menengah atas. KKN dilaksanakan pada tanggal 7 Agustus - 5 September 2018 dengan sasaran warga Kampung Pasir Putih RT 04/RW 04 diantaranya siswa-siswi MTS Anwarul Hidayah, MI Anwarul Hidayah, PAUD Anwarul Hidayah, TPA, ibu-ibu kader, ibuibu pengajian majelis ta'lim dan jama'ah Mushola Ar-Rohman.

secara lisan (Subagyo, 2011, p. 39). Peneliti juga melakukan observasi langsung kepada masyarakat sebagai suatu kegiatan membandingkan fakta dan budaya yang ada dilingkungan setempat. Observasi adalah proses pengumpulan informasi secara langsung, yang dilakukan secara langsung dengan cara mengamati aktivitas orangorang di tempat lokasi penelitian (Creswell, 2012, p. 213). Peneliti juga melakukan pendekatan, sosialisasi dan penyuluhan kepada masyarakat Desa Gunung Bunder II sesuai program yang sudah di rencanakan.

Rabu dan Jum'at. Kegiatan ini dilakukan di depan posko KKN kelompok 45 dengan sasaran siswa-siswi SD/MI, SMP/MTS. Tujuan dari program Ruang MACA adalah agar anak-anak di Desa Gunung Bunder II gemar untuk membaca sehingga mendapat ilmu dan informasi dari membaca. 

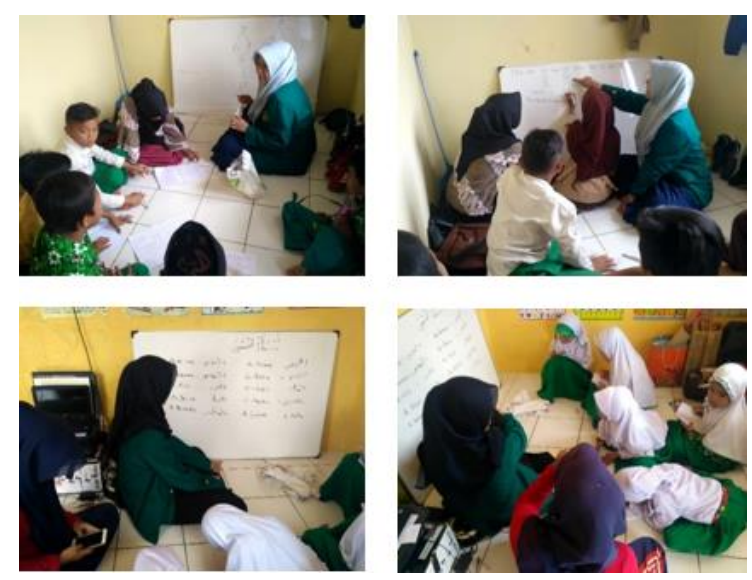

Sahabat Belajar Anak

Program kerja sahabat belajar anak dilaksanakan sejak tanggal 9 Agustus 2018 setiap hari senin sampai dengan sabtu. Program ini dilakukan di dalam ruang tamu posko KKN kelompok 45 dengan sasaran siswa-siswi SD/MI dan MTS. Tujuan dari program kerja sahabat belajar anak yaitu untuk membantu anak dalam menyelesaikan permasalahan didalam pembelajaran dan untuk mempermudah anak dalam mengerjakan soal - soal yang sulit di sekolahnya.

\section{Penyuluhan Menabung Sejak Usia Dini}

Program penyuluhan menabung sejak usia dini dilaksanakan pada tanggal 21 Agustus 2018 dengan sasaran Anak-anak PAUD Anwarul Hidayah. Tujuan dari kegiatan ini adalah memberikan penyuluhan tentang pentingnya menabung sejak dini dan menjelaskan manfaat dari menabung usia dini kepada anak sehingga dapat memotivasi anak-anak dalam menabung.
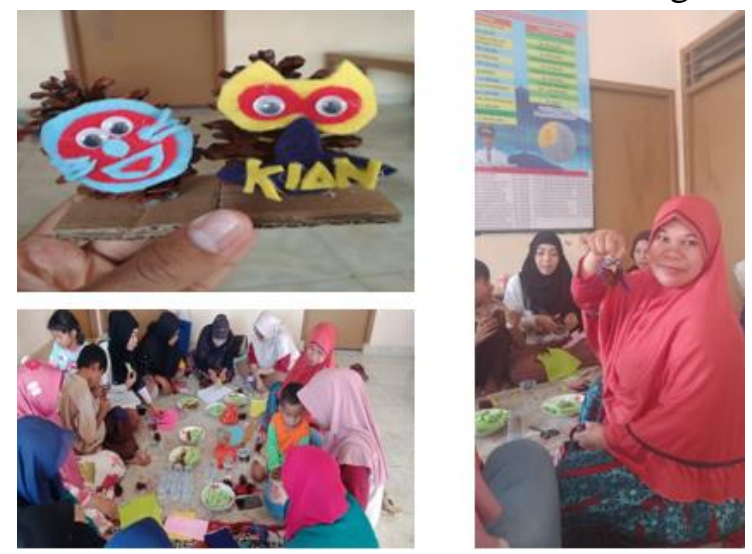

Ekonomi Kreatif
Program kerja ekonomi kreatif dilaksanakan pada tanggal 31 Agustus 2018 di Kantor Desa dengan sasaran ibu-ibu kader dan sekolah perempuan. Tujuan dibuatnya program tersebut yaitu untuk mengetahui kreatifitas masyarakat Desa Gunung Bunder II dengan memanfaatkan hasil alam yang ada di Desa Gunung Bunder II dan menjadikannya sebagai salah satu cinderamata khas Desa Gunung Bunder II.
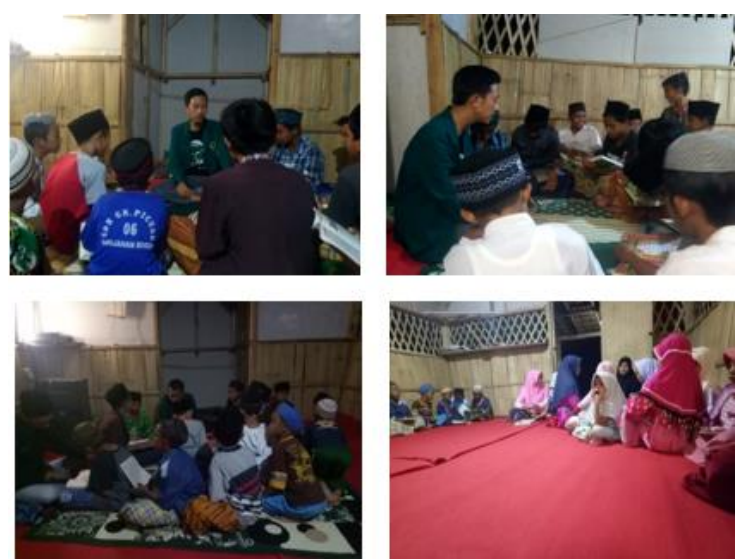

Pengajaran di TPA

Prorgram kerja pengajaran TPA di laksanakan pada tanggal 25 Agustus 2018 di TPA Desa Gunung Bunder II. Tujuan dari program kerja pengajaran TPA agar anak-anak di desa Gunung Bunder II dapat memahami dan dapat membaca Al-qur'an dengan baik dan benar sesuai dengan tajwidnya.

\section{Sodaqoh Ke Mushola}

Program kerja sodaqoh dilaksanakan pada tanggal 2 September 2018 dengan sasaran Mushola Ar-Rohman. Tujuan diadakannya program kerja sodaqoh berupa Mukena dan Al-Qur'an yaitu untuk memberikan kemudahan dalam beribadah kepada masyarakat atau musafir yang sedang berkunjung ke Desa Gunung Bunder II. 

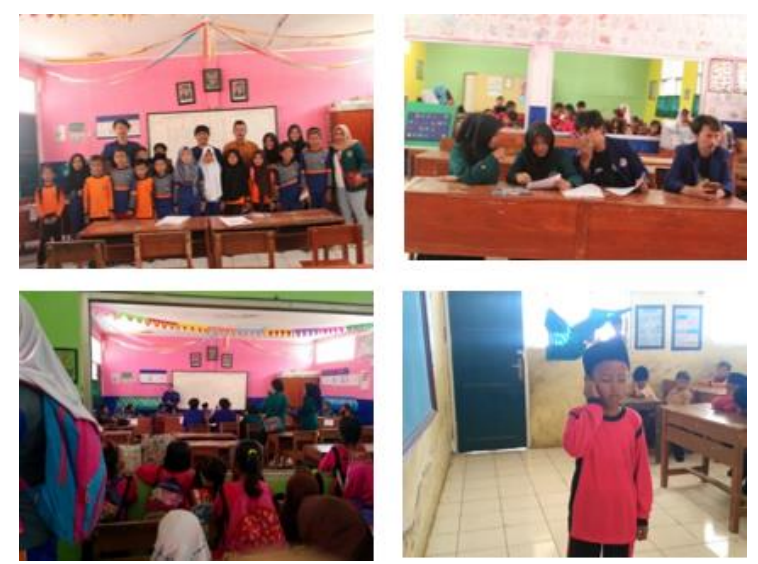

Perlombaan Menjelang Idul Adha

Program kerja perlombaan menjelang Idul Adha di laksanakan pada tanggal 18 Agustus 2018 di SDN 04 Gunung bunder II. Program kerja perlombaan ini dilaksanakan dengan tujuan agar anak-anak di desa Gunung bunder II bersemangat dalam menjalankan perintah agamanya dan mampu menjadikan kegiatan keagamaan sebagai kebutuhan yang penting dari bagian kehidupan di masa depan.
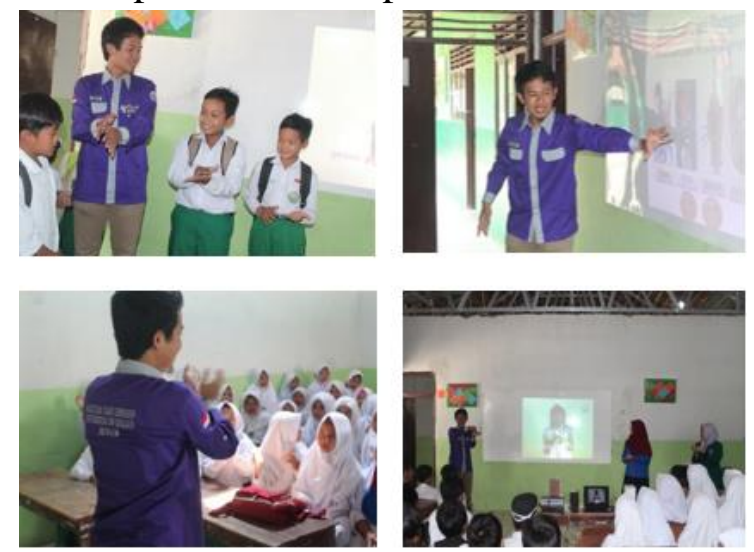

Penyuluhan Cuci Tangan Pakai Sabun

Program kerja penyuluhan ini dilaksanakan pada tanggal 13 Agustus 2018 dengan sasaran siswa-siswi MI Anwarul Hidayah. Tujuan dari kegiatan penyuluhan ini yaitu sebagai usaha pencegahan (Preventif) dari berbagai macam penyakit, serta untuk meningkatkan derajat kesehatan (Promotif) siswa-siswi MI Anwarul Hidayah.
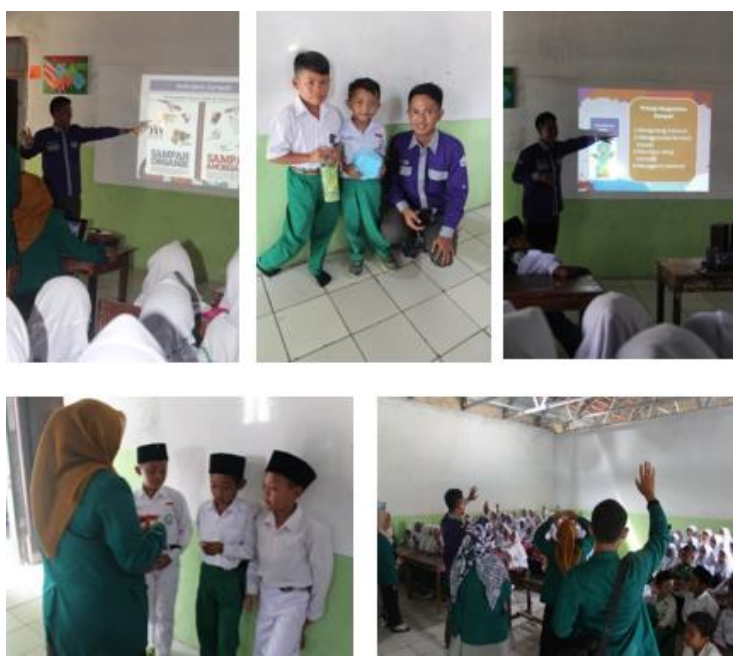

\section{Penyuluhan Kesehatan Lingkungan}

Program kerja penyuluhan kesehatan dilaksanakan pada tanggal 27 Agustus 2018 di MI Anwarul Hidayah dengan sasaran siswa/siswi MI Anwarul Hidayah. Program ini bertujuan untuk memberikan edukasi atau pendidikan kepada siswa/siswi MI Anwarul Hidayah agar terbiasa sejak dini untuk menjaga lingkungan sekitar terutama dalam hal membuang sampah dan pengelolaan sampah.
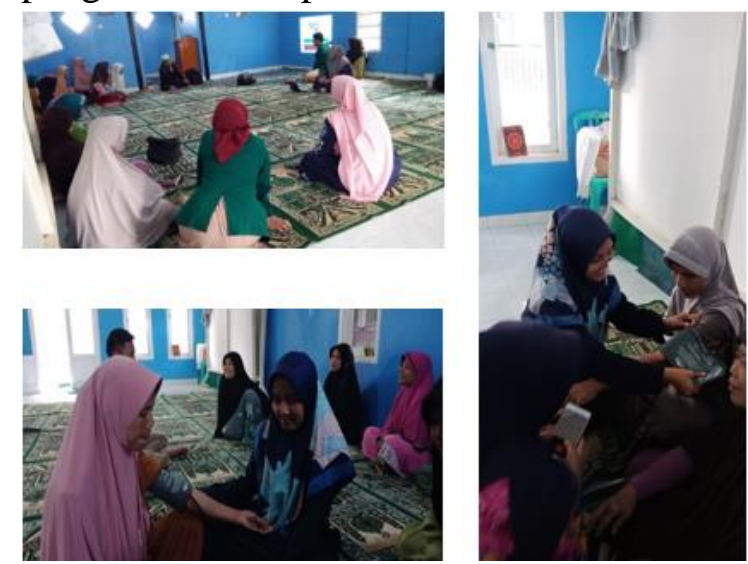

Pemeriksaan Kesehatan (Tekanan Darah)

Program kerja pemeriksaan kesehatan dilaksanakan pada tanggal 28 Agustus 2018 di Mushola Ar-rahman dengan sasaran ibubu majelis ta'lim. Tujuan dari program ini yaitu agar ibu-ibu mengetahui kondisi tekanan darahnya, mengetahui penyebab dan cara pencegahan penyakit Hipertensi melalui perilaku C-E-R-D-I-K (Cek kesehatan berkala, Enyahkan asap rokok, 
Rajin berolahraga, Diet seimbang, Istirahat yang cukup, Kendalikan stress).
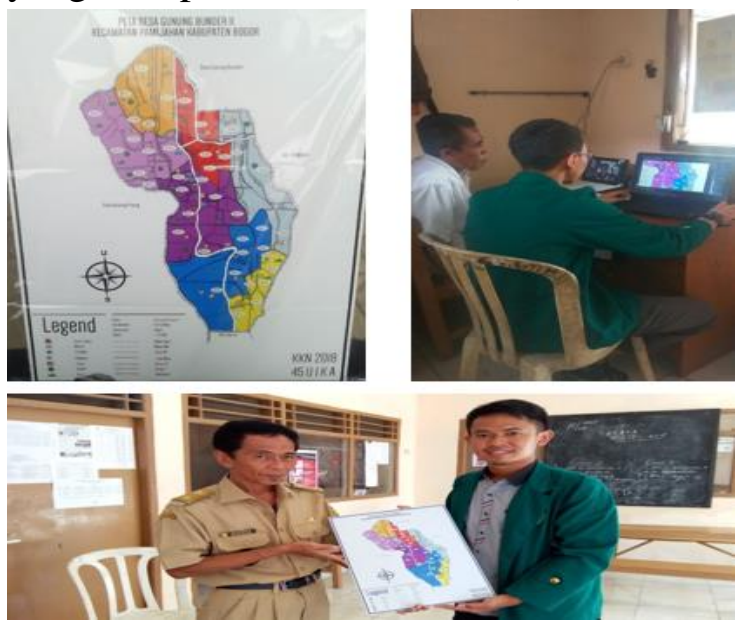

\section{Peta Lokasi}

Program ini dilaksanakan pada tanggal 26 Agustus sampai dengan 30 Agustus 2018 di Desa Gunung Bunder II, Kecamatan Pamijahan. Tujuan dari pembaruan peta ini adalah untuk memperjelas denah lokasi Gunung Bunder II serta untuk mengetahaui ruang lingkup RT/RW setempat dengan mudah.
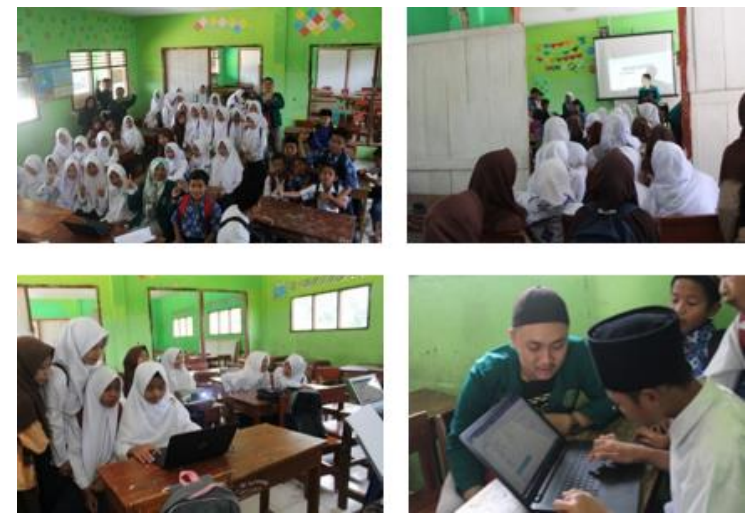

Pengenalan Microsoft Office

\section{KESIMPULAN}

Kesimpulan yang dapat diambil dari pelaksanaan program kuliah kerja nyata (KKN) yang berlokasikan di Desa Gunung Bunder II, Kecamatan Pamijahan, Kabupaten Bogor adalah kegiatan KKN merupakan akses mahasiswa untuk menyalurkan ilmu yang diperoleh dari Universitas kepada masyarakat. Selain itu, KKN mendidik mahasiswa untuk
Program kerja pengenalan Microsoft office dilaksanakan pada tanggal 31 Agusutu 2018 di MTS Anwarul HIdayah dengan sasaran siswa-siswi kelas 7. Tujuan dari program kerja ini adalah untuk mensosialisasikan kepada anak-anak Desa Gunung Bunder II bahwa sangat pentingnya penguasaan software Microsoft office khususnya Microsoft word untuk digunakan agar membantu proses pekerjaan dengan mudah dan efisien.
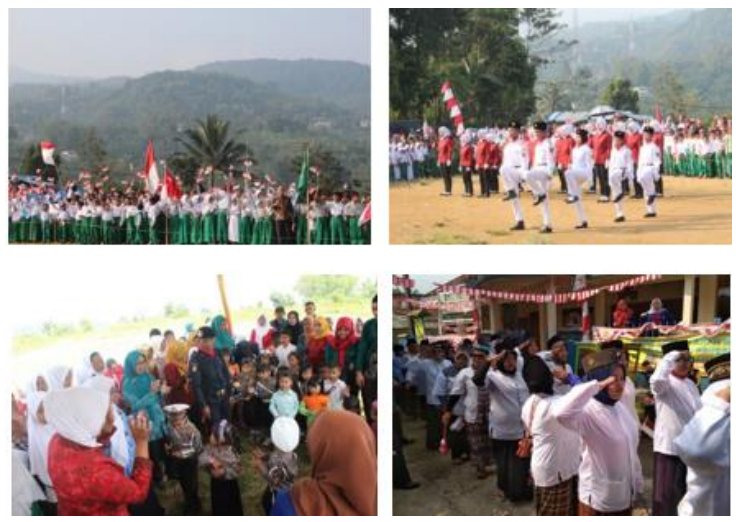

\section{Program Momen Besar}

Program momen besar ini merupakan program HUT RI Ke 73 yang dilaksanakan pada tanggal 16-21 Agustus 2018 di Desa Gunung Bunder II, Kecamatan Pamijahan. Sasaran dari program kerja HUT RI Ke 73 ini adalah seluruh warga Desa Gunung Bunder II dengan tujuan agar generasi penerus bangsa dapat mengohormati jasajasa para pahlawan dan dapat mengamalkan nilai-nilai baik dari perjuangan para pahlawan.

senantiasa meningkatkan dan menjaga kerjasama serta menumbuhkan tingkat kepedulian sosial yang tinggi terhadap berbagai permasalahan yang dihadapi masyarakat dan pembangunan yang mewujudkan mencerdaskan kehidupan dan kesejahteraan masyarakat. Program kerja yang di rencanakan oleh penulis sudah terlaksana sesuai dengan waktu yang telah 
ditentukan dengan dukungan dan partisipasi masyarakat Desa Gunung Bunder II dan kerjasama antar penulis.

\section{SARAN}

Dengan tujuan untuk memberikan masukan serta partisipasi demi kemajuan dalam meningkatkan taraf dan mutu Desa Gunung Bunder II, peneliti memberikan beberapa saran kepada masyarakat Desa Gunung Bunder II yang diharapkan dapat berguna untuk peningkatan mutu dan kualitas semua pihak, yaitu; kepada masyarakat Desa Gunung Bunder II dapat memelihara dan menjaga tali silaturahmi, rasa persaudaraan, kerjasama dan semangat gotong-royong. Diharapkan masyarakat dapat melanjutkan program-program yang telah dilaksanakan oleh mahasiswa KKN Universitas Ibn Khaldun Bogor dan dapat

\section{DAFTAR PUSTAKA}

Creswell, J. W. (2012). Educational Research : Planning, Conducting, and Evaluating Quantitative and Qualitative Research . Boston: Pearson.

Subagyo, P. J. (2011). Metodologi Penelitian Dalam Teori dan Praktek . Jakarta: Aneka Cipta. meningkatkan kerjasama lintas sektor. Masyarakat dan pihak desa aktif bekerja sama dalam mengembangkan program kerja desa yang sudah ada dibuat oleh desa, dengan masukan di adakannya program untuk generasi muda - remaja yang diharapkan akan menjadi penentu kemajuan desa dikemudian hari. Adanya kontrol kerja desa dengan teknologi yang sudah berkembang, seperti rencana program desa, program yang sudah terlaksana, program yang selesai di bangun, jumlah kependudukan, kepengurusan desa agar program desa dapat terlaksana dan terkontrol lebih baik.

Suyono, H., \& Haryanto, R. (2009). PEDOMAN PELAKSANAAN KKN POS PEMBERDAYAAN KELUARGA (POSDAYA). Depok: CITRA KHARISMA BUNDA. 